\title{
New Frontiers in the Treatment of Perfectionism
}

Roz Shafran, Ph.D., Anna Coughtrey, Ph.D., and Radha Kothari, Ph.D.

University College London

Address for correspondence: Professor R. L. Shafran, UCL Institute of Child Health, London WC1N 1EH 


\begin{abstract}
Perfectionism can present as a clinical problem in its own right or it can interfere with the successful treatment of Axis 1 disorders. In the last 15 years, a cognitive behavioural analysis of 'clinical perfectionism' has been proposed. This approach and the measurement of the construct of clinical perfectionism have proved controversial. Nevertheless, the approach has experimental support and clinical utility; the derived treatment has been shown to lead to significant improvement on both measures of perfectionism and Axis 1 disorders. The cognitive behavioural intervention has been evaluated in a range of formats (group, individual, face-to-face and online) and all show promise. Further work is required to address clinically important questions such as when to treat clinical perfectionism if it occurs in the context of single and multiple Axis 1 disorders.
\end{abstract}

\title{
INTRODUCTION
}

Despite decades of research, there is little consensus as to the nature and function of perfectionism, and how it should best be defined and conceptualised in a healthcare setting. Healthy striving for excellence can be associated with success and achievement in a range of fields including sport (Gotwals, Stoeber, Dunn \& Stoll, 2012; Stoeber \& Otto, 2006). However, perfectionism is also recognised to have a negative impact in multiple domains including mental health (Egan, Wade, \& Shafran, 2011; Shafran \& Mansell, 2001). The literature refers to 'healthy and unhealthy' perfectionism (e.g., Stumpf \& Parker, 2000), 'normal vs. neurotic' perfectionism (Hamachek, 1978), 'functional and dysfunctional' perfectionism (Rhéaume et al., 2000) and 'positive and negative' perfectionism (Terry-Short, Owens, Slade \& Dewey, 1995). 'Healthy', 'normal', 'functional' or 'positive' perfectionism 
can be considered as healthy striving for achievement, taking enjoyment in the consequential hard work, and setting realistic and flexible standards. This type of perfectionism is typically studied by personality rather than psychopathology researchers, and there is a rich literature describing its characteristics, associations and function. In contrast, and unsurprisingly, clinical researchers have focused on the unhealthy, neurotic, dysfunctional, negative perfectionism as this is the type associated with psychopathology and warrants psychological intervention. It is this type of perfectionism that is therefore focused upon in this paper.

\section{Definitions and Descriptions}

Horney (Homey, 1950) described perfectionism as the "Tyranny of the shoulds," while Ellis and Harper labelled it "Musterbation" (Ellis \& Harper, 1961). These apt descriptions can easily be related to by people with mental health disorders and perfectionism. More recent definitions have emphasised the association of perfectionism with self-worth and self-evaluation. Burns, for example defined perfectionists as "Those whose standards are high beyond reach or reason, people who strain compulsively and unremittingly toward impossible goals and who measure their own worth entirely in terms of productivity and accomplishment. For these people, the effort for excellence is self-defeating." (Burns, 1980, p. 34). Frost and colleagues (1990) defined perfectionism as the "Setting of excessively high standards for performance accompanied by overly critical self-evaluation" (Frost, Marten, Lahart \& Rosenblate, 1990, p. 450). Hewitt and Flett (1991) consider that perfectionism comprises dimensions of self-oriented perfectionism (unrealistic standards and perfectionistic motivation for the self), other-oriented perfectionism (unrealistic standards and perfectionistic motivations for others), and socially prescribed perfectionism (the belief that significant others expect oneself to be perfect). Numerous other dimensions or types of perfectionism described in the literature include self-critical perfectionism (e.g., Dunkley \& 
Blankstein, 2000), perfectionist self-presentation (e.g., Hewitt, Flett \& Ediger, 1995) and even 'learning perfectionism' (Yang \& Chen, 2013).

Despite the wealth of research and interest in the nature and characteristics of perfectionism and the undeniable volume of data demonstrating its associations with psychopathology (Egan, Wade, \& Shafran, 2011; Shafran \& Mansell, 2001), only 15 years ago there was almost no research on how it should be best treated using established psychological methods such as cognitive behaviour therapy (CBT). With a focus on the type of perfectionism that was presenting in routine clinical settings for difficulties such as eating disorders, Shafran, Cooper and Fairburn (2002) described a type of perfectionism termed 'clinical perfectionism'. The core psychopathology of this type of perfectionism was described as "the overdependence of self-evaluation on the determined pursuit of personally demanding self-imposed standards in at least one highly salient domain despite adverse consequences" (Shafran et al., 2002, p. 778). The primary motivation for describing this type of perfectionism was the hope that it would have direct implications for the development of an intervention for use in routine clinical practice.

\section{Measurement}

The two most widely used measures of perfectionism are multidimensional (Frost et al., 1990; Hewitt \& Flett, 1991). The Frost Multi-dimensional Perfectionism Scale (Frost et al., 1990) was developed using theoretically based items and items from existing measures (Burns, 1980; Garner, Olmstead, \& Polivy, 1983; Hodgson \& Rachman, 1977) and consists of subscales assessing concern over mistakes, doubts about actions, personal standards, parental expectations, parental criticism, and organisation. The measure has been found to be both reliable and valid for use with non-clinical and clinical populations (Frost et al., 1990; Hewitt \& Flett, 1991; Hewitt, Flett, Turnbull-Donovan, \& Mikail, 1991). The Multi- 
dimensional Perfectionism Scale developed by Hewitt and Flett assesses self-oriented perfectionism (e.g., "I demand nothing less than perfection for myself"), socially prescribed perfectionism (e.g., "People expect nothing less than perfection from me) and other oriented perfectionism (e.g., If I ask someone to do something, I expect it to be done flawlessly") (Hewitt \& Flett, 1991). The measure has been found to have acceptable psychometric properties in both clinical and non-clinical samples, including concurrent validity, temporal stability and internal consistency (Hewitt \& Flett, 1991; Hewitt, Flett, Turnball-Donovan \& Mikhail, 1991).

Neither of these two widely used measures have a time-frame which is entirely reasonable considering that they were not designed to assess change with treatment. However, in order to measure the construct of clinical perfectionism and its change with treatment, the Clinical Perfectionism Questionnaire was developed. This twelve item scale assesses the domains in which the perfectionism is expressed, and rates the cognitions and behaviours associated with perfectionism; its psychometric properties are currently being established (Chang \& Sanna, 2012; Dickie, Sturgnor, Wilson \& McDowell, 2012; Egan et al., 2014).

\section{Why Perfectionism is a Problem}

Dysfunctional perfectionism can be problematic for at least four reasons. First, it can interfere with functioning in its own right. From a clinical perspective, it is associated with many practical difficulties and negative emotional consequences. Individuals high in unhelpful perfectionism often spend a great deal of time doing and re-doing things, or spend more time than is necessary on a task due to their high standards and fear of making mistakes. This can leave little time for other aspects of life, leading to social isolation and a narrowing of interests, which may in turn cause low mood. Performance anxiety is relatively typical, and 
may be present in both work and social contexts. Fear of making mistakes and an inability to meet high standards can also lead to procrastination and avoidance of tasks, causing high levels of anxiety. At the extreme, this problematic behaviour may mean that the individual is unable to finish academic assignments or complete tasks at work, and can even lead to unemployment and an inability to engage effectively in day to day tasks.

Second, perfectionism is associated with and/or elevated across a range of disorders, including obsessive compulsive disorder, social anxiety disorder, panic disorder, generalised anxiety disorder, posttraumatic stress disorder, body dysmorphic disorder, chronic fatigue syndrome, eating disorders, major depression, bipolar disorder and suicidal ideation and behaviour (Egan, Wade \& Shafran, 2011; Egan, Wade, Shafran \& Anothy, 2014).

Third, perfectionism may impede the treatment of Axis 1 disorders such as depression and bulimia nervosa. For example, in a study of 239 patients with depression, perfectionism significantly predicted negative outcome, for both psychological and pharmacological treatments (Blatt, Quinlan, Pilkonis \& Shea, 1995). Pre-treatment self-critical perfectionism was significantly associated with negative treatment outcome in 53 patients with chronic pain, even after taking into account pre-treatment levels of depression (Kempke, Luyten, Van Wambeke, Coppens \& Morlion, 2014). In anorexia nervosa, perfectionism is associated with poorer outcome after hospital admission (Bizuel, Sadowsky \& Riguad, 2001) and with treatment drop-out (Sutandar-Pinnock, Carter, Olmsted \& Kaplan, 2003). However, it is also the case that dysfunctional levels of perfectionism do not always interfere with treatment progress and can decline with the successful treatment of the Axis 1 disorder (e.g., Ashbaugh et al., 2007).

Finally, perfectionism is a problem since it increases risk of developing an eating disorder and depression. A number of studies have shown that perfectionism increases and maintains eating disorder pathology (Egan et al., 2011). For example, in a prospective study, 
perfectionism predicated increased bulimic symptoms in female students over a three month period (Steele, Corsini \& Wade, 2007). Twin studies have demonstrated that female co-twins of individuals with anorexia nervosa had higher levels of perfectionism and perfectionism and self-evaluation based on weight and shape (a diagnostic criterion for anorexia nervosa and bulimia nervosa), indicating a shared genetic risk (Wade \& Bulik, 2007; Wade, Tiggemann, Bulik, Fairburn, Wray \& Martin, 2008). There is also evidence that perfectionism is a vulnerability factor for depression (Egan et al., 2011). In prospective studies, perfectionism has been found to predict an increase in depressive symptoms in individuals with clinical depression, mediated by negative social support, negative social interactions and avoidant coping (Dunkley, Sanislow, Grilo \& McGlashan, 2006; 2009). In a four year prospective study of 150 community adults, self-critical perfectionism predicted depression symptoms, mediated by sadness in response to daily stress (Mandel, Dunkley \& Moroz, 2015).

Given the difficulties presented by perfectionism, the next question is how it should best be conceptualised and treated. Advances in effective psychological treatment have followed a particular course in which theories, experimental science and clinical innovation benefit each other in reciprocal relationships (Clark, 2004). A key aspect of such treatment development is to focus on specific psychopathology to be able to identify the putative maintaining mechanisms and potential methods of reversing them.

\section{Cognitive Behavioural Model of Clinical Perfectionism}

Following the principles for successful treatment development, a cognitive behavioural maintenance model of perfectionism was proposed by the Oxford Centre for Research on Eating Disorders, led by Christopher Fairburn. The model was developed with the specific goal of advancing the treatment of the specific type of perfectionism that was seen in routine 
clinical practice. Even considering perfectionism in terms of cognitive and behavioural maintaining mechanisms was rather radical, given widespread view that perfectionism was an immutable personality characteristic. According to the cognitive behavioural account, people with clinical perfectionism determinedly pursue personally demanding standards in at least one highly salient domain despite adverse consequences because their self-evaluation is almost exclusively dependent on striving and achieving. As a result of the overdependence of self-evaluation on such striving and achievement, people with clinical perfectionism set standards, operationalised as rules, 'musts' or 'shoulds' that dominate their lives. They also engage in extensive striving behaviour to prevent their feared occurrence - failure - from occurring. Such behaviour includes repeated checking, avoidance, procrastination, listmaking and excessive thoroughness.

The cognitive behavioural account proposes that the evaluation of whether people with perfectionism have met their standards is subject to numerous, well-established cognitive biases such as attention to failure at the expense of success, discounting of success and dichotomous thinking. As a result, the account suggests that the majority of people with perfectionism often perceive that they have failed. They react to this failure with intense selfcriticism, emotional arousal, anxiety, low mood, and often hopelessness as well as further counter-productive behaviour such as increased checking.

According to this account, clinical perfectionism is maintained by the expressions of the core psychopathology of perfectionism i.e., rigid standards expressed as rules, cognitive biases and negative self-evaluation, self-criticism and fear of failure (Shafran et al., 2010), see Figure 1.

--INSERT FIGURE 1 HERE--.

Reaction to the cognitive behavioural model of clinical perfectionism 
The initial reaction from researchers in the field to the cognitive model of clinical perfectionism was far from positive. A flurry of criticism arose, with Hewitt and Flett arguing that perfectionism is not unidimensional (Hewitt et al., 2003). Our response to that criticism was that clinical perfectionism and multidimensional perfectionism were different constructs (Shafran et al., 2003) and subsequently other researchers became embroiled in the argument (Dunkley, Blankstein, Masheb \& Grilo, 2006; Stoeber and Damian, 2014). We would like to take this opportunity to make two key points unambiguously clear. First, we have never suggested that clinical perfectionism is 'unidimensional'. By definition, it has cognitive, affective and behavioural aspects to it. As such, there is no reason to expect that the Clinical Perfectionism Questionnaire would only have one factor. In our view, studies that show that the Clinical Perfectionism Questionnaire only has one factor in no way invalidate the construct of clinical perfectionism. Second, of course other dimensions of perfectionism such as socially oriented perfectionism can also be clinical problems. The term 'clinical perfectionism' was never intended to imply it that having high standards for other people, or the belief that others have high standards for you cannot be clinical issues for some patients. There is a need for interventions to address such problems, but the focus of the model of clinical perfectionism was purposefully highly specific and its primary test was the clinical utility that derived from such a construct.

\section{Evaluation of the Cognitive Behavioural Model of Clinical Perfectionism}

Cognitive biases. A number of experimental studies have demonstrated the role of attention and interpretation biases in the maintenance of perfectionism. For example, a comparison of students, athletes and a clinical group found that dichotomous thinking, a 
maintenance factor in the model of clinical perfectionism, accounted for significant variance in perfectionism (Egan, Piek, Dyck \& Rees, 2007). A study on the biased interpretation of ambiguous information found that people with high levels of perfectionism showed interpretation biases consistent with the model and that these were specific to perfection relevant material (Yiend, Savulich, Coughtrey \& Shafran, 2011). Koboroi and Tanno (2012) compared high and low perfectionists on an emotional Stroop task and found that the high perfectionism group took significantly longer than the low perfectionism group to colour name the negative perfectionism-relevant words, consistent with the possibility that perfectionists may attend disproportionately to negative perfectionism relevant information.

Performance related perfectionist behaviours. Experimental studies of task performance have also revealed significant differences in performance between high and low perfectionists. When asked to sort beads, participants who had completed an interpretation training task designed to induce high perfectionist thinking took longer to complete the task, sorted fewer beads, and were more likely to check their work, compared to participants who had completed a low perfectionism interpretation task. Similarly, when asked to copy passages of text and geometric shapes, high perfectionists took significantly longer than low perfectionists (Yiend et al., 2011). Questionnaire and interview analyses provided a more fine-grained understanding of the nature of the behavioural expressions of the core psychopathology including a range of counterproductive safety behaviour such as checking, excessive time spent on a task and being over-thorough (Lee et al., 2011). An earlier study on manipulating personal standards through a behavioural experiment resulted in changes in eating behaviours and attitudes in a community sample of women (Shafran, Lee, Payne \& Fairburn, 2006). 
Self-criticism and counter-productive behaviours following "failure". Studies have consistently demonstrated an association between self-criticism and goal progress. There is a positive association between self-oriented perfectionism and goal progress, when selfcriticism iss controlled (Powers, Koestner, Zuroff, Milyavskaya \& Gorin, 2011). Furthermore, self-oriented and socially prescribed perfectionism is associated with higher shame and guilt following task failure (Stoeber, Kempe \& Keogh, 2008), consistent with the idea that individuals with clinical perfectionism are likely to be self-critical following failure, leading to feelings of shame and guilt. When compared to individuals with adaptive levels of perfectionism, people with maladaptive levels of perfectionism also demonstrated higher levels of emotional distress and dysfunctional thinking, as well as lower levels of task persistence, when asked to complete a brief anagram task under levels of high evaluative threat (Lo \& Abbott, 2013). Qualitative studies of clinical perfectionism highlight the important role of setting rigid rules, avoidance and self-criticism following failure, in the maintenance of the overdependence of striving for success in self-evaluation (Riley \& Shafran, 2005). More recently, the link between clinical perfectionism and eating psychopathology was supported in female athletes with the role of self-criticism being highlighted as key (Shanmugam and Davies, 2015).

Reappraisal of standards following "success". In an experimental task, individuals with perfectionism re-evaluated their standards after receiving feedback of success and were more likely to select a more difficult goal for the subsequent task following attainment of their standards (Kobori, Hayakawa \& Tanno, 2009). This evidence of 'raising the bar' is consistent with the model's hypothesis that the reappraisal of standards following the temporary meeting of personal standards, increases the likelihood of failure, resulting in further selfcriticism and maintenance of an overdependence of self-worth based on success and performance (Shafran et al., 2002). 


\section{Overview of Cognitive Behavioural Therapy for Clinical Perfectionism}

An indirect test of the cognitive behavioural account is the efficacy of cognitive behavioural therapy deriving from the model. The treatment that derived from the theory was designed to be used as a stand-alone intervention or as adjunct to evidence-based treatments for other forms of psychopathology if clinical perfectionism is seen as a barrier to change. According to the model, clinical perfectionism will impede the successful treatment of Axis I disorders if the domains overlap. This could explain the discrepant findings with regard to whether perfectionism interferes with treatment outcome for the Axis 1 disorder

CBT for perfectionism typically involves 10 sessions delivered over 8 weeks, with the first six sessions bi-weekly, followed by three weekly sessions and a fortnight's gap between the final two sessions. The treatment manual describes the principles and methods of treatment and should be used flexibly, with an emphasis on a personalised formulation which develops and evolves as treatment progresses (Egan, Wade, Shafran \& Antony, 2014). There is a focus on maintaining mechanisms, not aetiology (unless needed), a strong emphasis on behaviour change and a range of interventions available to broaden the patient's scheme for self-evaluation. This includes behavioural experiments to test competing hypotheses, and using cognitive-behavioural methods to address personal standards, self-criticism, and cognitive biases that maintain clinical perfectionism (see Egan et al., 2014 for further details).

Treatment typically begins with psychoeducation and monitoring. This includes providing information to patients about the relationship between effort and performance, and about the role of repeated performance checking in magnifying relevant concerns, maintaining negative self-evaluation, decreasing confidence in memory and focusing attention on the aspects of the task which cause the most anxiety, which serves to maintain and possibly increase preoccupation. Counter-productive safety behaviours, such as making lists, multi-tasking, and 
ensuring 'everything is in place' before beginning a task are also discussed in relation to maintaining maladaptive beliefs. These discussions, along with information obtained from monitoring, inform and develop the individualised formulation further, in a dynamic iterative process. Behavioural experiments (including surveys) are used to decrease problematic behaviour. Rigidity, rules, extreme standards cognitive biases and the dysfunctional scheme for self-evaluation are examined using a variety of cognitive and behavioural techniques. If clients engage in repeated checking, behavioural experiments to demonstrate that checking causes doubt can be extremely powerful (Radomsky, Dugas, Alcolado \& Lavoie, 2014; Radomsky, Shafran, Coughtrey \& Rachman, 2010). A variety of specific methods to address self-criticism are utilised including an adaptation of the 'Coach Analogy' (Hoffman \& Otto, 2008) and developing a self-compassionate and respectful response to perceived failure as an alternative to self-criticism. There is a strong focus on homework throughout treatment, in order for patients to translate learning in session to everyday life. However, the nature of clinical perfectionism means that patients can be over-thorough, frequently fear that their homework will be "wrong," and commonly engage in black and white thinking (e.g. 'If I can't do it perfectly, I won't do my homework at all'), all of which can all lead to difficulties with homework. These should be incorporated into the cognitive-behavioural formulation and based on the analysis of clinical perfectionism. Treatment concludes with relapse prevention and a focus on the future.

\section{Efficacy and Effectiveness of CBT for Perfectionism}

There is a growing body of evidence that indicates that perfectionism can be successfully targeted through cognitive-behavioural interventions. These studies have used a variety of designs (including single case experimental designs and randomised controlled trials) In one of the first studies of patients with clinical anxiety and depression, a single case experimental 
design series found that ten sessions of CBT resulted in clinically significant improvement in levels of perfectionism and a reduction in symptoms of depression, but no improvements in symptoms of anxiety (Glover, Brown, Fairburn, \& Shafran, 2007). Similar findings were found in a later study of four participants which included a stable baseline and session-bysession outcome measures (Egan \& Hine, 2008). In a later, small randomised controlled trial of CBT for clinical perfectionism in patients with anxiety and/or depression, treatment led to clinically significant improvements in perfectionism for $75 \%$ of patients and the number of participants meeting diagnostic criteria for anxiety or depression halved following treatment, compared to no change in diagnostic status in wait-list control participants (Riley, Lee, Cooper, Fairburn \& Shafran, 2007).

In the last few years there has been growing interest in evaluating the effect of CBT for perfectionism such that a meta-analysis of eight studies could be conducted (Lloyd et al., 2014). The meta-analysis found that CBT was effective at reducing symptoms of perfectionism and Axis I disorders, with large pre-post intervention effect sizes according to Cohen's (1988) criteria for change in personal standards and concern over mistakes and medium effective sizes found for changes in symptoms of anxiety and depression (Lloyd et al., 2014). Since that time, a further four studies have been added to the meta-analysis with the same conclusion, showing large effect sizes for perfectionism and medium effect sizes for associated Axis 1 disorders (Lloyd et al., unpublished thesis).

The majority of research into the treatment of perfectionism has focused on CBT as a stand-alone intervention. A pilot study has investigated the effects of adding group CBT for perfectionism as an adjunct for standard eating disorders treatment in a sample of 61 inpatients (Goldstein, Peters, Thornton \& Touyz, 2014). Results supported the effectiveness of overall treatment but suggested that adding an intervention for perfectionism did not enhance treatment outcome for in-patients with anorexia nervosa. However, it is unclear 
whether these findings are due to ceiling effects of an already efficacious treatment, or whether the separate targeting of perfectionism is not needed to effectively treat eating disorders.

\section{Recent developments in Theory and Practice}

\section{Development of Low Intensity Interventions}

Given the development of stepped care models of intervention for other psychopathology, there has been recent interest in the development of low-intensity CBT for perfectionism including guided self-help, group CBT and web-based and computerised approaches.

Self-Help: Pleva and Wade (2007) found that guided self-help and pure self-help were both effective in producing clinically significant reductions in perfectionism and symptoms of anxiety and depression in a non-clinical sample, although guided self-help was superior. There is also some indication that symptoms of bulimia nervosa can be effectively reduced through guided self-help for perfectionism, without directly focusing on these symptoms in treatment. In a randomised controlled trial of eight sessions of guided self-help for perfectionism, CBT for perfectionism produced significant decreases in bulimic behaviours as well as anxiety and depression (Steele \& Wade, 2008).

Group CBT: A case series of 21 patients with maladaptive perfectionism found that group CBT for clinical perfectionism was beneficial, but that psychoeducation alone was not effective for reducing perfectionism or negative affect (Steele, Waite, Egan, Finnigan, Handley \& Wade, 2013). A six session cognitive behavioural group intervention targeting perfectionism was efficacious in reducing overall perfectionism, concern over mistakes and personal standards in adults with anorexia nervosa in an inpatient setting. These changes were independent of changes in body mass index (Lloyd, Fleming, Schmidt, \& Tchanturia, 2014). 
Computerised and internet based CBT: Given the increased need and desire for online interventions, an online version of CBT for perfectionism (where participants work independently without guidance from a therapist) has also been developed and tested. Webbased CBT for perfectionism has resulted in significant decreases in anxiety, depression and perfectionism (Radhu, Zafiris, Arpin-Cribbie, Irvine \& Ritvo, 2012). However, though this online intervention led to a reduction in symptoms of perfectionism in this study, another study found it was less effective than the face-to-face version of the treatment at maintaining this change at a six month follow-up (Egan, van Noort, et al., 2014).

\section{Prevention of Perfectionism}

As a growing body of evidence indicates the key role of perfectionism as a transdiganostic feature of multiple psychological disorders, there has been a move towards targeting maladaptive perfectionism in non-clinical populations in order to prevent development of negative affect and other psychopathology. Initial studies of cognitivebehavioural coaching in non-clinical university students indicated that levels of unhelpful perfectionism significantly reduced following a six week workshop course, and this reduction was sustained at four-week follow-up (Kearns, Forbes \& Gardiner, 2007). Similarly, university students who attended an eight-week group focusing on changing attitudes, beliefs, feelings and interpersonal interactions affected by perfectionism, experienced a significant reduction in their levels of depression, anxiety and perfectionism compared to students who did not attend the group (Kutlesa \& Arthur, 2008). Although these findings are promising, given that most adults with psychopathology identify symptoms in childhood and adolescence, prevention programmes may be better focused on young people.

A preliminary study of female adolescents indicated that an eight-lesson programme targeting unhelpful perfectionism produced significant effects for concern over mistakes and personal standards, compared to control classes. Young girls who were at high risk of 
developing eating disorders (i.e. reporting high levels of shape and weight concern at baseline) were more likely to benefit from the perfectionism prevention programme (Wilksch, Durbridge \& Wade, 2008). Furthermore, in a large study of almost 700 adolescents, young people who received an intervention designed to reduce unhelpful perfectionism and promote compassion reported significantly lower unhelpful perfectionism, self-criticism and negative affect at six-month follow-up compared to controls. However, significant differences between groups were only maintained at 12-month follow-up for unhelpful perfectionism (Nehmy \& Wade, 2015). Another study from the same group found that a 2 session perfectionism intervention was successful in reducing some key aspects of perfectionism in a younger age group (mean 11.6 years) of 125 students, and these gains were maintained for 4 weeks (Fairweather-Schmidt \& Wade, 2015). These preliminary findings suggest that unhelpful perfectionism can be successfully targeted in prevention programmes; however, further investigation of the long-term effects of perfectionism prevention on negative affect and psychopathology is needed.

\section{Emerging Trends/ Issues for the Field/ Future Directions}

The work on treatment of perfectionism is in its infancy. A number of important clinical questions require data to address them. For example, when perfectionism exists in the context of an Axis 1 disorder, in which cases should it be treated and when will it decline without additional input but in association with the successful treatment of an Axis 1 disorder? When perfectionism seems to be a common transdiagnostic maintaining factor for a range of psychopathology (e.g., depression, anxiety, OCD), is it effective and efficient to target the perfectionism? What is the relationship between perfectionism and self-esteem? How should we treat the other aspects of perfectionism such as socially oriented perfectionism? Can the methods used to address rigidity and perfectionism be applied to other disorders such as autism? How do we treat perfectionism in children and adolescents? One review indicated 
that future research on the treatment of perfectionism in young people may benefit from focusing on the role of parental anxiety and parent-child relationships (Morris \& Lomax, 2014); however there are currently no studies using the cognitive behavioural approach with younger people. This is an obvious gap. The list is long but funding is short and priorities for research will need to ensure that the interventions are cost-effective as well as clinically valuable.

\section{Conclusions}

In conclusion, the work on perfectionism has not been without its controversy, and undoubtedly mistakes have been made along the way. However, twenty years ago there was no guidance about how the problem was best understood and addressed, and now there is an explosion of clinical and research interest from around the world, and an intervention which is accessible and makes a difference to people's lives. 
Figure 1. The cognitive-behavioural model of clinical perfectionism

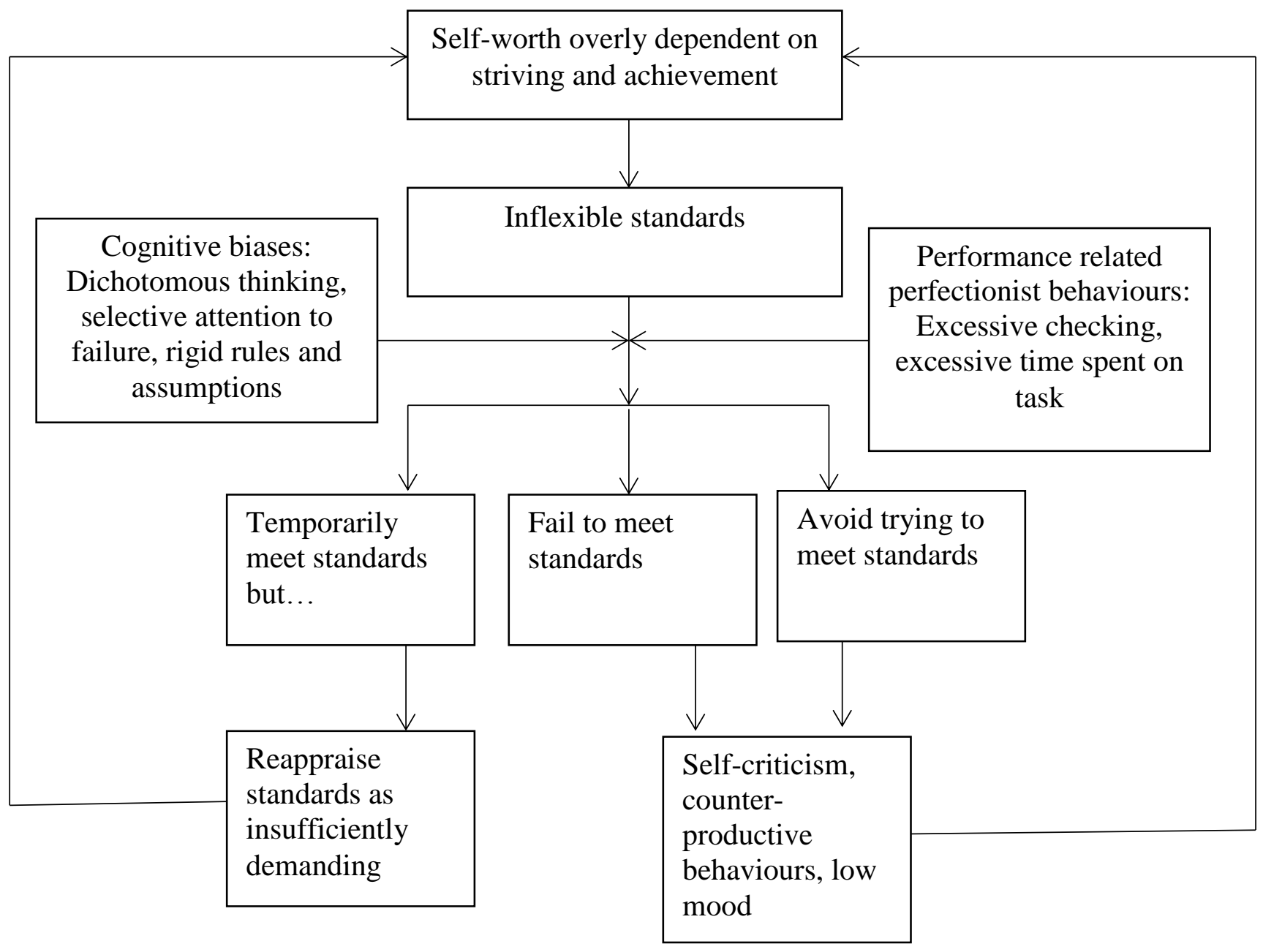




\section{References}

Aldea, M., Rice, K., Gormley, B., \& Rojas, A. (2010). Telling perfectionists about their perfectionism: Effects of providing feedback on emotional reactivity and psychological symptoms. Behaviour Research and Therapy, 48, 1194-1203.

Ashbaugh, A., Antony, M. M., Liss, A., Summerfeldt, L. J., McCabe, R. E., \& Swinson, R. P. (2007). Changes in perfectionism following cognitive-behavioral treatment for social phobia. Depression and Anxiety, 24(3), 169-177.

Bieling, P. J., Israeli, A. L., \& Antony, M. M. (2004). Is perfectionism good, bad, or both? Examining models of the perfectionism construct. Personality and individual differences, 36(6), 1373-1385.

Bizuel, C., Sadowsky, N., \& Riguad, D. (2001). The prognostic value of EDI scores in anorexia nervosa patients: A prospective follow-up study of 5-10 years. European Psychiatry, 16, 232-238.

Burns, D. (1980). The perfectionist's script for self defeat.(1980). Psychology Today, 34-51.

Chang, E. C., \& Sanna, L. J. (2012). Evidence for the validity of the Clinical Perfectionism Questionnaire in a nonclinical population: More than just negative affectivity. Journal of personality assessment, 94(1), 102-108.

D. M. Clark (2004).Developing new treatments: on the interplay between theories, experimental science and clinical innovation. Behaviour Research and Therapy, 42, 1089-1104.

Cohen, J. (1988). Statistical power for the behavioural sciences: Second edition. Hillsdale, NJ: Erlbaum.

Dickie, L., Surgenor, L. J., Wilson, M., \& McDowall, J. (2012). The structure and reliability of the Clinical Perfectionism Questionnaire. Personality and Individual Differences, 52(8), 865-869.

Dunkley, D. M., \& Blankstein, K. R. (2000). Self-critical perfectionism, coping, hassles, and current distress: A structural equation modeling approach. Cognitive Therapy and Research, 24(6), 713-730.

Dunkley, D. M., Blankstein, K. R., Masheb, R. M., \& Grilo, C. M. (2006). Personal standards and evaluative concerns dimensions of "clinical" perfectionism: A reply to Shafran et al.(2002, 2003) and Hewitt et al.(2003). Behaviour research and therapy, 44(1), 6384.

Dunkley, D. M., Sanislow, C. A., Grilo, C. M., \& McGlashan, T. H. (2006). Perfectionism and depressive symptoms three years later: Negative social interactions, avoidant coping, and perceived social support as mediators. Comprehensive Psychiatry, 47, 106-115.

Dunkley, D. M., Sanislow, C. A., Grilo, C. M., \& McGlashan, T. H. (2009). Self-criticism vs neuroticism in predicting depression and psychosocial impairment for 4 years in a clinical sample. Comprehensive Psychiatry, 50, 335-346.

Egan, S.J., \& Hine, P. (2008). Cognitive behavioural treatment of perfectionism: A single case experimental design series. Behaviour Change, 25, 245-258.

Egan, S. J., Hattaway, M., \& Kane, R. T. (2014). The relationship between perfectionism and rumination in post traumatic stress disorder. Behavioural and cognitive psychotherapy, 42(02), 211-223.

Egan, S.J., Piek, J.P., Dyck, M.J., \& Rees, C.S. (2007). The role of dichotomous thinking and rigidity in perfectionism. Behaviour Research and Therapy, 45, 1813-1822. 
Egan, S. J., Shafran, R., Lee, M., Fairburn, C. G., Cooper, Z., Doll, H. A., ... \& Watson, H. J. (2014). The reliability and validity of the clinical perfectionism questionnaire in eating disorder and community samples. Behavioural and cognitive psychotherapy, 113.

Egan, S. J., van Noort, E., Chee, A., Kane, R. T., Hoiles, K. J., Shafran, R., \& Wade, T. D. (2014). A randomised controlled trial of face to face versus pure online self-help cognitive behavioural treatment for perfectionism. Behaviour Research and Therapy, 63, 107-113.

Egan, S. J., Wade, T. D., \& Shafran, R. (2011). Perfectionism as a transdiagnostic process: A clinical review. Clinical Psychology Review, 31(2), 203-212.

Egan, S.J., Wade, T.D., Shafran, R., \& Antony, M.M. (2014). Cognitive behavioural treatment of perfectionism. New York: Guilford Press.

Ellis, A., \& Harper, R. (1961). A guide to rational living. New York: Riverhead Books.

Fairweather-Schmidt, A. K., \& Wade, T. D. (2015). Piloting a perfectionism intervention for pre-adolescent children. Behaviour research and therapy, 73, 67-73.

Frost, R. O., Marten, P., Lahart, C., \& Rosenblate, R. (1990). The dimensions of perfectionism. Cognitive therapy and research, 14(5), 449-468.

Garner, D. M., Olmstead, M. P., \& Polivy, J. (1983). Development and validation of a multidimensional eating disorder inventory for anorexia nervosa and bulimia. International Journal of Eating Disorders, 2(2), 15-34. doi: 10.1002/1098108x(198321)2:2<15::aid-eat2260020203>3.0.co;2-6

Glover, D. S., Brown, G. P., Fairburn, C. G., \& Shafran, R. (2007). A preliminary evaluation of cognitive-behaviour therapy for clinical perfectionism: A case series. British Journal of Clinical Psychology, 46(1), 85-94.

Goldstein, M., Peters, L., Thornton, C.E., Touyz, S.W. (2014). The treatment of perfectionism within the eating disorders: A pilot study. European Eating Disorders Review, 22,(3), 217-221.

Gotwals, J. K., Stoeber, J., Dunn, J. G., \& Stoll, O. (2012). Are perfectionistic strivings in sport adaptive? A systematic review of confirmatory, contradictory, and mixed evidence. Canadian Psychology/Psychologie canadienne, 53(4), 263-279.

Hamachek, D. E. (1978). Psychodynamics of normal and neurotic perfectionism. Psychology: A Journal of Human Behavior. 15, 27-33.

Hewitt, P. L., \& Flett, G. L. (1991). Perfectionism in the self and social contexts: conceptualization, assessment, and association with psychopathology. Journal of personality and social psychology, 60(3), 456-470.

Hewitt, P. L., Flett, G. L., \& Ediger, E. (1995). Perfectionism traits and perfectionistic selfpresentation in eating disorder attitudes, characteristics, and symptoms. International Journal of Eating Disorders, 18(4), 317-326.

Hewitt, P. L., Flett, G. L., Besser, A., Sherry, S. B., \& McGee, B. (2003). Perfectionism Is Multidimensional: a reply to. Behaviour Research and Therapy, 41(10), 1221-1236.

Hewitt, P.L., Flett, G.L., Turnball-Donovan, W., \& Mikhail,. S.F. (1991). The multidimensional perfectionism scale: Reliability, validity and psychometric properties in psychiatric samples. Psychological Assessment, 3, 464-468.

Hodgson, R., \& Rachman, S. (1977). Obsessional-compulsive complaints. Behaviour Research and Therapy, 15, 389 - 395.

Hoffman, S.G., \& Otto, M.W. (2008). Cognitive behavioral therapy for social anxiety

disorder: Evidence-based and disorder-specific treatment techniques. New York, NY: Routledge.

Homey, K. (1950). Neurosis and human growth: New York: Norton. 
Kearns, H., Forbes, A., \& Gardiner, M. (2007). A cognitive behavioural coaching intervention for the treatment of perfectionism and self-handicapping in a non-clinical population. Behaviour Change, 24, 157-172.

Kempke, S., Luyten, P., Van Wambeke, P., Coppens, E., \& Morlion, B. (2014). Self-critical perfectionism predicts outcome in multidisciplinary treatment for chronic pain.Pain Practioner, 14, (4), 309-314.

Kobori, O., Hayakawa, M., \& Tanno, Y. (2009). Do perfectionists raise their standards after success? An experimental examination of the revaluation of standard setting in perfectionism. Journal of Behaviour Therapy and Experimental Psychiatry, 40(4), $515-521$.

Kobori, O., \& Tanno, Y. (2012). Self-oriented perfectionism and its relationship to selective attention: An experimental examination using social cogniive paradigm. Japanese Psychological Research, 54,(4), 418-423.

Kutlesa, N., \& Arthur, N. (2008). Overcoming negative aspects of perfectionism through group therapy. Journal of Rational-Emotive and Cognitive-Behavioural Therapy, 26(3), 134-150.

Lee, M., Roberts-Collins, C., Coughtrey, A., Phillips, L., \& Shafran, R. (2011). Behavioural expressions, imagery and perfectionism. Behavioural and cognitive psychotherapy, 39(04), 413-425.

LLoyd, S. (2014). Perfectionism in Anorexia Nervosa: performance based evidence, the relationship with other features of the disorder, familial and treatment aspects. Unpublished Ph.D. thesis.

Lo, A., \& Abbott, M.J. (2013). The imapct of manipulating expected standards of performance for adapative, maladaptive and non-perfectionists. Cognitive Therapy and Research, 37(4), 762-778.

Morris, L., \& Lomax, C. (2014). Review: Assessment, development and treatment of childhood perfectionism: A systematic review. Child and Adolescent Mental Health, 19(4), 225-234.

Nehmy, T.J., \& Wade, T.D. (2015). Reducing the onset of negative affect in adolescents: Evaluation of a perfectionism program in a universal prevention setting. Behaviour Research and Therapy, 67, 55-63.

Owens, R. G., \& Slade, P. D. (2008). So perfect it's positively harmful? Reflections on the adaptiveness and maladaptiveness of positive and negative perfectionism. Behavior Modification, 32, 928-937

Pleva, J., \& Wade, T.D. (2007). Guided self-help versus pure self-help for perfectionism: A randomised contolled trial. Behaviour Research and Therapy, 45, 849-861.

Powers, T.A., Koestner, R., Zuroff, Milyavskaya \& Gorin (2011). The effects of selfcriticism and self-oriented perfectionism on goal pursuit Personality and Social Psychology Bulletin, 37, 964-75.

Radomsky, A. S., Dugas, M. J., Alcolado, G. M., \& Lavoie, S. L. (2014). When more is less: Doubt, repetition, memory, metamemory, and compulsive checking in OCD. Behaviour research and therapy, 59, 30-39.

Radomsky, A. S., Shafran, R., Coughtrey, A. E., \& Rachman, S. (2010). Cognitive-behavior therapy for compulsive checking in OCD. Cognitive and Behavioral Practice, 17(2), 119-131.

Radhu, N., Zafiris, J.D., Arpin-Cribbie, C.A., Irvine, J., \& Ritvo, P. (2012). Evaluating a web0based cognitive-behavioural therapy for maladaptive perfectionism in unveristy students. ournal of American College Health, 60, 357-366. 
Rhéaume, J., Freeston, M. H., Ladouceur, R., Bouchard, C., Gallant, L., Talbot, F., \& Vallières, A. (2000). Functional and dysfunctional perfectionists: are they different on compulsive-like behaviors?. Behaviour Research and Therapy, 38(2), 119-128

Riley, C. \& Shafran, R. (2005). Clinical perfectionism: A preliminary qualitative analysis. Behavioural and Cognitive Psychotherapy, 33, 369-374.

Riley, C., Lee, M., Cooper, Z., Fairburn, C. G., \& Shafran, R. (2007). A randomised controlled trial of cognitive-behaviour therapy for clinical perfectionism: A preliminary study. Behaviour Research and Therapy, 45(9), 2221-2231.

Shafran, R., Cooper, Z., \& Fairburn, C. G. (2002). Clinical perfectionism: a cognitivebehavioural analysis. Behaviour Research and Therapy, 40(7), 773-791. doi: http://dx.doi.org/10.1016/S0005-7967(01)00059-6

Shafran, R., Cooper, Z., \& Fairburn, C. G. (2003). "Clinical perfectionism" is not "multidimensional perfectionism": A reply to Hewitt, Flett, Besser, Sherry \& McGee. Behaviour Research and Therapy, 41(10), 1217-1220.

Shafran, R., Egan, S. J., \& Wade, T. D. (2010). Overcoming Perfectionism: A self help manual using cognitive behavioural strategies. London: Constable and Robinson.

Shafran, R., Lee, M., Payne, E., \& Fairburn, C.G. (2006). The impact of manipulating personal standards on eating attitudes and behaviour. Behaviour Research and Therapy, 44, 897-906.

Shafran, R., \& Mansell, W. (2001). Perfectionism and psychopathology: A review of research and treatment. Clinical Psychology Review, 21(6), 879-906.

Shanmugam, V., \& Davies, B. (2015). Clinical perfectionism and eating psychopathology in athletes: The role of gender. Personality and Individual Differences, 74, 99-105.

Steele, A., Corsini, N., \& Wade, T. D. (2007). The interaction of perfectionism, perceived weight status and self-esteem to predict bulimic symptoms: The role of 'benign' perfectionism. Behaviour Research and Therapy, 45, 1647-1655.

Steele, A.L., \& Wade, T.D. (2008). A randomised trial investiating guided self-help to reduce perfectionism and its impact on bulimia nervosa: A pilot study. Behavioural and Cognitive Psychotherapy, 41, 129-143.

Steele, A. L., Waite, S., Egan, S. J., Finnigan, J., Handley, A., \& Wade, T. D. (2013). Psychoeducation and group cognitive-behavioural therapy for clinical perfectionism: a caseseries evaluation. Behavioural and Cognitive Psychotherapy,41(02), 129-143.

Stoeber, J., \& Damian, L. E. (2014). The Clinical Perfectionism Questionnaire: Further evidence for two factors capturing perfectionistic strivings and concerns. Personality and Individual Differences, 61, 38-42.

Stoeber, J., Kempe, T., \& Keogh,E.J. (2008). Facets of self-oriented and socially prescribed perfectionism and feelings of pride, shame and guilt following success and failure. Personality and Individual Differences, 44, 1506-1516.

Stoeber, J., \& Otto, K. (2006). Positive conceptions of perfectionism: Approaches, evidence, challenges. Personality and Social Psychology Review, 10(4), 295-319.

Stumpf, H., \& Parker, W. D. (2000). A hierarchical structural analysis of perfectionism and its relation to other personality characteristics. Personality and individual differences, 28(5), 837-852.

Sutandar-Pinnock, K., Woodside, D. B., Carter, J. C., Olmsted, M. P., \& Kaplan, A. S. (2003). Perfectionism in anorexia nervosa: A 6-24 month follow up study. International Journal of Eating Disorders, 33, 225-229

Terry-Short, L. A., Owens, R. G., Slade, P. D., \& Dewey, M. E. (1995). Positive and negative perfectionism. Personality and individual differences, 18(5), 663-668.

Vohs, K. D., Bardone, A.M., Joiner, T. E., \& Abramson, L. Y. (1999). Perfectionism, perceived weight status and self-esteem interact to predict bulimic symptoms: A 
model of bulimic symptom development. Journal of Abnormal Psychology, 103, 695-700.

Wade, T. D., \& Bulik, C. M. (2007). Shared genetic and environmental risk factors between undue influence of body shape and weight on self-evaluation dimensions of perfectionism. Psychological Medicine, 37, 635-644.

Wade, T. D., Tiggemann, M., Bulik, C. M., Fairburn, C. G., Wray, N. R., \& Martin, N. G. (2008). Shared temperament risk factors for Anorexia Nervosa: A twin study. Psychosomatic Medicine, 70, 239-244.

Wilksch, S.M., Durbridge, M.R., \& Wade, T.D. (2008). A preliminary controlled comparison of programs designed to reduce risk of eating disorders targeting perfectionism and media literacy. Journal of the American Academy of Child and Adolescent Psychiatry, 47(8), 939-947.

Yang, H., \& Chen, J. (2013). Learning Perfectionism and Learning Burnout in a Primary School Student Sample: A Test of a Learning-Stress Mediation Model. Journal of Child and Family Studies, 1-9.

Yiend, J., Savulich, G., Coughtrey, A.E., \& Shafran, R. (2011). Biased interpretation in perfectionism and its modification. Behaviour, Research and Therapy, 49(12), 892900. 